https://www.journal-imab-bg.org

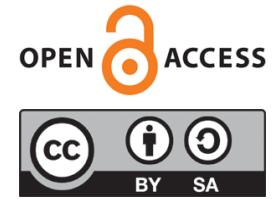

Original article

\title{
FUNCTIONAL RECOVERY AFTER SURGICALLY TREATED FRACTURES OF THE ANKLE JOINT
}

\author{
Petya Parashkevova, Radoslava Deleva, \\ Department Public Health, Faculty Public health and health care, University \\ of Ruse, Bulgaria.
}

\section{ABSTRACT:}

Purpose: Ankle fractures are one of the most common injuries of the musculoskeletal system. They account for approximately $10 \%$ of all fractures, and many studies show that their incidence is increasing. The aim of the report is to monitor the functional recovery of patients with surgically treated ankle fractures using AOFAS.

Methods: We conducted clinical work with patients in the period 2019 - 2021. The study included 34 patients with ankle fractures treated surgically. The average age is 37.8 years. The monitored period of functional recovery for each patient was 2 months.

Results: To establish the functional condition and to objectify the treatment results, we applied the American Orthopaedic Foot \& Ankle Society (AOFAS). The test consists of 9 questions divided into 3 categories: pain (40 points), function (50 points) and alignment (10 points). Results are reported as standard deviations with $95 \%$ confidence intervals. We conducted the study, reporting the category "Pain" at rest and while moving. The initial data from AOFAS are 32.04(at rest) / 23.51 (when moving) points, which means a very limited function of the ankle joint. At the end of the follow-up period, the results were respectively $84.02 / 77.84$ points, which shows a significant improvement in the functional capabilities of patients.

Conclusions: Based on the results obtained from the applied methodology for physiotherapy recovery, it can be said that the developed physiotherapy program of special exercises combined with manual mobilization techniques has a beneficial effect in restoring the arthrokinematics of the ankle-foot complex.

Keywords: ankle joint, ankle fractures, postoperative physiotherapy, American Orthopaedic Foot \& Ankle Society (AOFAS),

\section{INTRODUCTION}

The ankle-foot complex is one of the most used areas of the human musculoskeletal system. Its structure is consistent with ensuring stability and mobility in the distal part of the lower limb [1]. The human ankle complex is a complex mechanical structure containing 28 bones, 33 joints (20 of which are actively articulated) and more than a hundred muscles and tendons.

The ankle joint is a joint that has multi-directional mobility due to its complex role in maintaining the body's weight and performing countless daily functions. It is a combination of bones and ligaments structured around the talus. It includes the tibia, fibula, calcaneus, tibiofibular ligament, lateral ligament complex and medial ligament complex. The talocrural joint is the place where the distal part of the tibia, the distal part of the fibula and the talus articulate. [2,3]

Ankle fractures are one of the most common injuries of the musculoskeletal system. They account for approximately $10 \%$ of all fractures, and many studies show that their incidence is increasing [4].

The aim of the report is to monitor the functional recovery of patients with surgically treated ankle fractures using AOFAS.

\section{MATERIALS AND METHODS:}

The structure of the ankle-foot area is consistent with ensuring stability and mobility in the distal part of the lower limb. On the one hand, the foot must bear the weight of the body when standing, and on the other hand, to provide a stable foundation for the body. It has the ability to adapt to uneven terrain while walking and thus acts as a shock absorber, absorbing the reaction forces of the support. [5, 6]

The ankle complex is formed by the composite articulations of the talocrural, distal tibiofibular and subtalar joints. Although the structures and functions of these 3 joints are often described separately, there is a complex relationship between them, and they cannot be separated. [7]

The talocrural joint is the junction of three bone structures: the distal ends of the tibia and fibula and the tricus of the talus. The tibia and fibula are elastically connected by the ligament structures of syndesmosis (interosseous membrane), anterior, posterior and transverse tibiofibular ligaments [8]. Powerful connections stabilize the joint against lateral tension:

- the lateral anterior fibulotalar ligament (AFTL), the fibulocalcaneal ligament (FCL) and the posterior fibulotalar ligament (PFTL), and

- medial-deltoid and calcaneonavicular ligament. [9]

Good congruence of the ankle joint is essential for its proper function, and all deviations in this direction of traumatic origin have an adverse effect, as they change the biomechanics of the joint and cause pathological compression stress $[10,11]$. 
Ankle fractures often affect people of creative age and are of great social significance. The distribution of this type of injury varies from active young patients to elderly patients, often with multiple comorbidities [12].

From an anatomical point of view, we distinguish:

- Tibial pylon fractures and

- Maleolar fractures

Fractures of the tibial pylon represent a bone lesion of the distal metaepiphyseal area of †the tibia and damage to the articular cartilage. These injuries account for about $1 \%$ of lower limb fractures and are usually associated with soft tissue involvement. Fractures are high-energy injuries and most often occur when falling from a height. [13; 14]

Muller and Nazarian [15] divided tibial pylon fractures into three groups: extraarticular, with partial involvement of joint surfaces, and intraarticular, with the destruction of the fibula diaphysis.

Maleolar fractures include damage to one maleol, two maleoles (bimaleolar) and trimaleolar (both maleoles and the distal posterior aspect of the tibia).

In fractures of the ankle joint, there is swelling, pain, deformity of the joint, abnormal mobility of the fragments. There may be a hematoma and swelling on the dorsal surface of the foot [16].

The dysfunctions that are observed after ankle fractures are:

- Limited range of motion

- Muscle weakness and decreased muscle endurance

- Painful burdening

- Gait disorders

- Limited locomotion [1]

Surgical treatment is used for displaced fractures of the medial and lateral malleolus, the presence of dislocation or subluxation of the joint, open fractures. The goal of treatment is to provide a stable anatomical reposition of the talus in the ankle fork, as even a $1 \mathrm{~mm}$ deviation leads to a significant loss of contact between the tibia and the talus, which can cause the development of early posttraumatic osteoarthritis.

The treatment consists of open repositioning of the fracture and placement of plates and screws for stable fixation. After the operation, the patient does not wear a cast and can move his ankle but does not step on it for 45-65 days.

\section{METHODOLOGY OF PHYSIOTHERAPY:}

The general scheme of applied physiotherapy is in accordance with the process of bone regeneration and soft tissue healing. It is conditionally divided into three phases:

Maximum-protective phase: there is swelling, pain, muscle guard, which are the main factors for impaired joint mobility and muscle strength. Physiotherapy includes: positional therapy, cryotherapy, PIR (post isometric relaxation), carefully controlled passive movements, minimal multiangular isometric contractions from a painless position for the muscles in the ankle joint, careful, controlled active-assisted movements and free active exercises in full volume and against resistance for the hip and knee joint.
Moderate-protective phase: swelling and muscle guard are significantly reduced, but the range of motion is limited. The main factor limiting the full restoration of joint mobility are the formed contractures and adhesions. To overcome the existing functional deficit, we apply: active exercises, muscle-inhibitory techniques (postural lesion stretching according to Janda, reciprocal inhibition, multiangular rhythmic stabilization), mobilizations according to Mullgan, mobilization stretching, isotonic exercises against manual resistance. The ankle complex, exercises against resistance by devices, exercises to restore the ability to work, balance and locomotor abilities and soft tissue mobilization for the operative scar.

Minimum protective phase: develops between the 4th and 6th postoperative weeks. It is characterized by motor deficit, associated mainly with unrestored muscle strength and limited mobility in the final sectors of the movement. Different degrees of joint instability can be observed. The main direction of physiotherapy during this phase is the complete recovery of muscle strength, the predominant development of stabilizing muscle contraction and the maximum functional recovery of the operated limb. The progression of strength training is based on: a smooth transition from submaximal to maximum resistance when performing the exercises; a transition from controlled to free concentric and eccentric exercises for coordination interaction in the open and closed kinetic chain and an increase in the duration of the healing procedures and the speed of the exercises. Stretching continues. Balance-board training is included, and initially, the patient is assisted by holding on to parallel bars. In the beginning, he stepped on a balance board with both feet and gradually moved to standing on one foot. Movements are practiced in different directions forward, backward and sideways. We give plyometric training. To improve the equilibrium reactions, we apply rhythmic stabilization - in the beginning, the patient is standing on two legs and gradually switches to standing only on the injured leg.

\section{RESULTS:}

We conducted clinical work with patients in the period 2019 - 2021. The study included 34 patients with ankle fractures treated surgically. There are 15 women and 19 men by sex. The average age is 37.8 years.

The monitored period of functional recovery for each patient was 2 months. Targeted physiotherapy begins after removal of the immobilization, on average about 45 days after surgery. The results at the beginning and at the end of the kinesitherapy treatment were analyzed.

To establish the functional condition and to objectify the treatment results, we applied the Scale for assessment of the foot and ankle of the American Orthopedic Association (AOFAS). The test consists of 9 questions divided into 3 categories: pain (40 points), function (50 points) and alignment (10 points). The total number of points from all components is 100 . The questions are both subjective and objective. The category of pain is subjective, while the category of alignment (responsible for the physiotherapist) is objective. However, the function cat- 
egory consists of 5-7 questions and requires an answer from both the patient and the therapist.

Results are reported as standard deviations with $95 \%$ confidence intervals.

We conducted the study, reporting the category "Pain" at rest and while moving. The initial data from AOFAS are 32.04 points (at rest) and 23.51 points (when moving), which means the very limited function of the ankle joint. At the end of the follow-up period, the results were respectively 84.02 points $/ 77.84$ points, which shows a significant improvement in the functional capabilities of patients (Fig. 1). The obtained values fof the mean, standard deviation, standard error and the coefficients of variation show that the scattering of the results is more pronounced in the initial studies.

Fig. 1. Mean AOFAS values at the beginning and end of the physiotherapy treatment

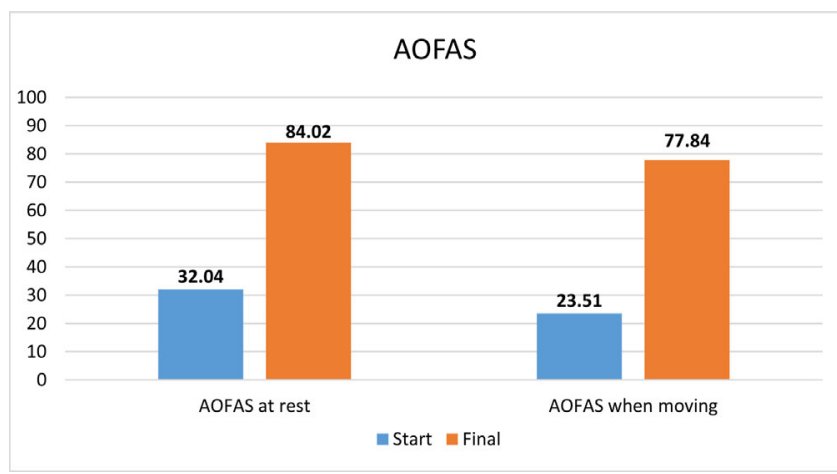

For a better assessment of the results, we will consider the three categories (pain, function and alignment) separately.

Pain is an important factor in limiting mobility in the ankle joint, especially in the early stages of recovery. In fig. 2, we present the results from the category "Pain".

In the initial examinations, the pain was of moderate intensity at rest (16.72 points) and significant during movement (8.24 points). The final results reveal a reduction in pain, as at rest, it is weak (32.06 p.) and moderate to weak when moving $(25.88 \mathrm{p})$.

Fig. 2. Mean values of the "Pain" category

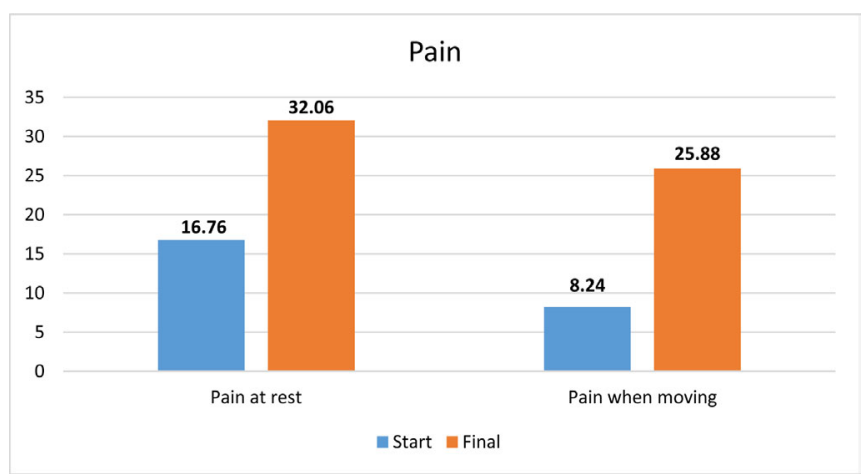

The function category includes 7 components with a total of 50 points: restriction of movements (need for help/ support) - 10 points, maximum distance traveled (number of steps) -5 points, walking on a flat surface -5 points, gait disturbance -8 points, flexion/extension -8 points, eversion/inversion - 6 points and ankle-walking stability - 8 points. In fig. 3 presents the results of a function study.

Fig. 3. Average values of the individual components in the "Function" category

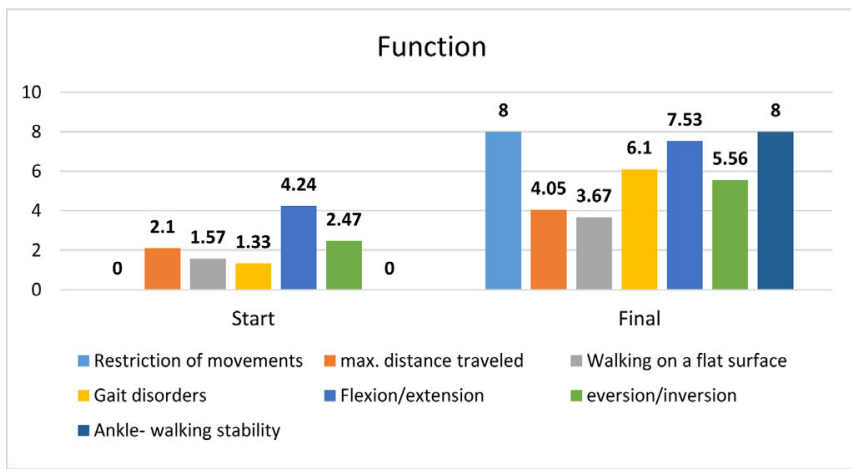

The data reveal that at the beginning of the study, the most limited is the independent movements without aids and the ankle-walking stability (0 points), then the walking on a flat surface and the gait. The movements in the sagittal plane are the least limited ( 4.24 points). The final results show a significant improvement in the function of the ankle joint, as some of the indicators have collected the maximum number of points (movement without aids and ankle-walking stability). The other indicators also increased significantly, approaching the maximum number of points. This proves the effectiveness of applied physiotherapy.

The last category is alignment, which carries a maximum of 10 points. The data from the study are presented in fig. 4.

Fig. 4. Mean values of the points in the category "Alignment"

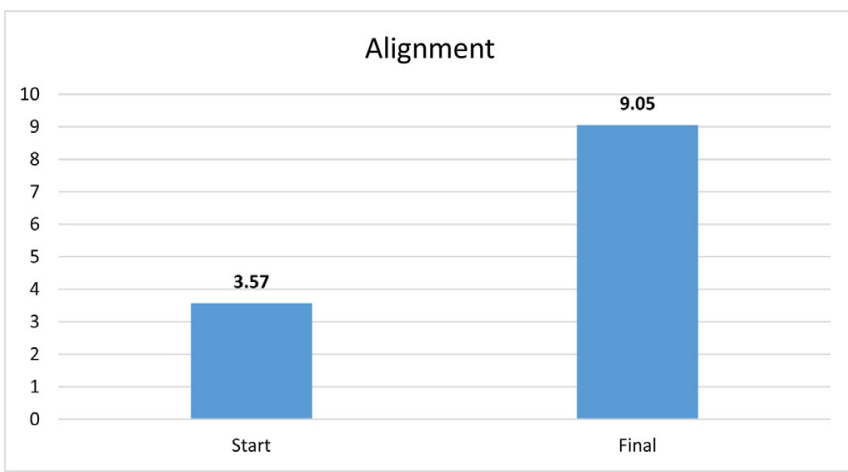

In the initial examinations, there was a significant deviation of the foot (3.57 points). With targeted physiotherapy at the end of the period, the data show significant improvement, and the foot is well aligned, without symptoms ( 9.05 points). We believe that this is due to the application of balance board exercises and plyometric training. 


\section{CONCLUSION:}

The functional recovery of the ankle-foot complex after operatively treated fractures is a complex and long process.

Based on the results obtained from the applied methodology for physiotherapy recovery, it can be said that the developed physiotherapy program of special exercises combined with manual mobilization techniques has a beneficial effect in restoring the arthrokinematics of the ankle-foot complex. This allows patients to fully return to normal household and work activities.

\section{REFERENCES:}

1. Popov N. [Kinesiology and pathokinesiology of the musculoskeletal system] [in Bulgarian] NSA-Press, Sofia. 2009, pp.241-255.

2. Brockett CL, Chapman GJ. (2016) Biomechanics of the ankle. Orthop Trauma. 30(3):232-238. [Internet]

3. Goost H, Wimmer MD, Barg A, Kabir K, Valderrabano V, Burger C. Fractures of the ankle joint: investigation and treatment options. Dtsch Arztebl Int. 2014 May 23;111(21): 377-88. [PubMed]

4. Court-Brown CM, Caesar B. Epidemiology of adult fractures: a review. Injury. 2006 Aug 1;37(8):691-697. [Crossref]

5. Becheva M, Georgiev D, Obrechkova D, Petrova V. Hippotherapy: integrated approach in children with cerebral palsy (CP). World $J$ Pharm Pharm Sci. 2016; 5(7):9-17. [Internet]

6. Holevic Y. (Editor) [Clinical orthopedics] [in Bulgarian] Sofia:
Medicina i Fizkultura. 2008, pp.32-41. 7. Medina McKeon JM, Hoch MC. The Ankle-Joint Complex: A Kinesiologic Approach to Lateral Ankle Sprains. J Athl Train. 2019 Jun; 54(6):589-602. [PubMed]

8. Yuen CP, Lui TH. Distal Tibiofibular Syndesmosis: Anatomy, Biomechanics, Injury and Management. Open Orthop J. 2017;11:670677. [PubMed]

9. Alves T, Dong Q, Jacobson J, Yablon C, Gandikota G. Normal and Injured Ankle Ligaments on Ultrasonography With Magnetic Resonance Imaging Correlation. J Ultrasound Med. 2019 Feb;38(2):513-528. [Crossref]

10. Thordarson DB, Motamed S, Hedman T, Ebramzadeh E, Bakshian IS. The effect of fibular malreduction on contact pressures in an ankle fracture malunion model. J Bone Joint Surg Am. 1997 Dec;79(12):1809-15 [PubMed]

11. Ramsey PL, Hamilton W.
Changes in tibiotalar area of contact caused by lateral talar shift. J Bone Joint Surg Am. 1976 Apr;5893):3567. [PubMed]

12. Mehta SS, Rees K, Cutler L, Mangwani J. Understanding risks and complications in the management of ankle fractures. Indian J Orthop. 2014 Sep;48(5):445-52 [PubMed]

13. Nieto E. Tibial pylon fracture associated with talus fracture and infrasindesmal spiral fibula. Case report and literature review. Int J Orthop Sci. 2020; 6(2):559-562 [Crossref]

14 Tomás-Hernández J. High-energy pilon fractures management: State of the art. EFORT Open Rev. 2017 Mar 13;1(10):354-361. [PubMed]

15. Muller ME, Nazarian S, Koch P, Schatzker J. The comprehensive classification of fractures of long bones. Springer-Verlag: Berlin. 1990., pp.148-149 [당sef]

16. Vladimirov B. (Editor) [Orthopedics, traumatology and orthotics] [in Bulgarian]. Znanie, Sofia. 2000, pp.158

Please cite this article as: Parashkevova P, Deleva R. Functional recovery after surgically treated fractures of the ankle joint. J of IMAB. 2022 Jan-Mar;28(1):4207-4210. DOI: https://doi.org/10.5272/jimab.2022281.4207

\author{
Address for correspondence: \\ Petya Andreeva Parashkevova, \\ "Angel Kanchev" University of Ruse \\ 8, Studentska Str., Ruse, Bulgaria. \\ E-mail: pparashkevova@uni-ruse.bg
}

